Roa Banquez, K., Rojas Torres, C. G. V., González Rincón, L. J., y Ortiz Ortiz, E. G. (mayoagosto, 2021). El docente en la era 4.0: una propuesta de formación digital que fortalezca el proceso de enseñanza y aprendizaje. Revista Virtual Universidad Católica del Norte, (63), 126-

160. https://www.doi.org/10.35575/rvucn.n63a6

\title{
El docente en la era 4.0: una propuesta de formación digital que fortalezca el proceso de enseñanza y aprendizaje
}

Teacher 4.0: A digital training proposal to strengthen the teaching and learning process.

\author{
Katherine Roa Banquez \\ Doctora en Educación \\ Departamento de Informática Educativa, Fundación Universitaria del Área Andina \\ Bogotá, Colombia \\ kroa@areandina.edu.co \\ Orcid: https://orcid.org/0000-0002-8474-8336 \\ Cvlac: \\ http://scienti.colciencias.gov.co:8081/cvlac/visualizador/generarCurriculoCv.do?cod_rh=0001333964
}

\section{Cielo Gilma Viviana Rojas Torres}

Magíster en Educación y Entornos Virtuales de Aprendizaje

Departamento de Informática Educativa, Fundación Universitaria del Área Andina

Bogotá, Colombia

crojas40@areandina.edu.co

Orcid: https://orcid.org/0000-0001-6647-2631

Cvlac: https://scienti.minciencias.gov.co/cvlac/visualizador/generarCurriculoCv.do?cod rh=0001510451

\section{Laura Johanna González Rincón}

Magíster en Educación y TIC

Departamento de Informática Educativa, Fundación Universitaria del Área Andina

Bogotá, Colombia

lgonzalez160@areandina.edu.co

Orcid: https://orcid.org/0000-0001-9304-515X

Cvlac: https://scienti.minciencias.gov.co/cvlac/visualizador/generarCurriculoCv.do?cod_rh=0001619457

\section{Edwin Germán Ortiz Ortiz}

Especialista en Teleinformática y en Gerencia de Proyectos de Sistemas de Información Departamento de Informática Educativa, Fundación Universitaria del Área Andina Bogotá, Colombia 
eortiz40@areandina.edu.co

Orcid: https://orcid.org/0000-0003-2865-6602

Cvlac: https://scienti.minciencias.gov.co/cvlac/visualizador/generarCurriculoCv.do?cod_rh=0001736030

Recibido: 30 de junio de 2020

Evaluado: 19 de octubre de 2020

Aprobado: 22 de febrero de 2021

Tipo de artículo: Investigación Científica y Tecnológica

\title{
Resumen
}

El presente estudio partió de la validación de un instrumento que permite diagnosticar el uso educativo de las tecnologías de la información y la comunicación (TIC) por parte de los docentes universitarios; este se basó en el modelo de competencia digital del profesorado universitario en el siglo XXI. El instrumento se aplicó a una muestra de 172 docentes, y los resultados se revisaron mediante un análisis factorial, en tres categorías: uso e impacto social de las TIC; diseño, gestión y evaluación de las TIC; y análisis e integración de las TIC en la formación, a partir de las cuales se realizó un proceso de triangulación concurrente (DITRIAC), con un enfoque mixto, asociando estas categorías al modelo de competencias TIC para el desarrollo profesional docente, planteado por el Ministerio de Educación de Colombia (MEN), y de esta forma construir un plan de formación

de competencias digitales pertinente para los docentes de la Fundación Universitaria del Área Andina, con un enfoque de aprendizaje basado en retos y contextualizado en las problemáticas evidenciadas en el quehacer docente.

Palabras Clave: Alfabetización Digital; Competencias Digitales; Formación Docente; Industria 4.0; Tecnologías; TIC.

\begin{abstract}
The present study started from the validation of an instrument that allows diagnosing the educational use of information and communication technologies (ICT) by university teachers; This was based on the model of digital competence of university teachers in the 21 st century. The instrument was applied to a sample of 172 teachers, and the results were reviewed through factor analysis, in three categories: use and social impact of ICT; ICT design, management and
\end{abstract}


evaluation; and analysis and integration of ICT in training, from which a concurrent triangulation process (DITRIAC) was carried out, with a mixed approach, associating these categories to the ICT competencies model for teacher professional development, proposed by the Ministry of Education of Colombia (MEN), and in this way to build a relevant digital skills training plan for teachers of the Fundación Universitaria del Área Andina, with a learning approach based on challenges and contextualized in the problems evidenced in the teaching work .

Keywords: Digital Literacy; Digital Competences; Teacher Training; Industry 4.0; Technology; ICT.

\section{Introducción}

El mundo en su continua transformación ha traído consigo un desarrollo de nuevas tecnologías, consolidadas en definición, procesos, tendencias, entre otros, que redundan en el entorno y que han sido popularizadas bajo intrincadas conceptualizaciones; no obstante, muy por el contrario, estas ofrecen un promisorio ramillete de funcionalidades en aplicaciones y herramientas que facilitan el uso en tareas, tanto básicas como especializadas, desarrolladas bajo el concepto de drones, inteligencia artificial, internet de las cosas, blockchain, entre otros, amenazando la habituación de procesos tradicionalistas; invasión que se suma en la denominada revolución 4.0, donde priman la interconexión y las redes como el pilar de la comunicación e interacción en la actual sociedad, y razón fundamental para que todos los ámbitos emerjan bajo sus principios (Agarwal, 2020; Pérez-Rojas, 2020). Es por ello que dicho evento trasciende el ejercicio pedagógico en todos sus estadios de formación (desde básica hasta educación superior), apuntando de manera directa a la trascendencia de la alfabetización digital y la competencia digital (Spante, et al., 2018) del docente en su práctica de aula; por lo mismo, surge la necesidad de su dominio y actualización continua, lo cual les permita a los docentes hacer uso eficiente de la misma, en aras de potencializar su quehacer diario.

España es uno de los países de la Unión Europea que más ha invertido en formación, y las encuestas siguen apuntando en cuanto a que los docentes afirman que no están formados para su utilización educativa (Cabero Almenara y Martínez Gimeno, 2019). Esto permite ver que la 
preocupación por el fortalecimiento de la formación docente es de carácter global y una necesidad apremiante.

Por su parte, en Colombia se identifican diferentes iniciativas por parte del Gobierno nacional; sin embargo, el común denominador entre estas iniciativas, es la limitación del alcance a instituciones educativas de nivel de básica primaria y secundaria; de hecho, a nivel universitario son las mismas universidades interesadas quienes han tomado la iniciativa de desarrollar diferentes proyectos alrededor de este tema, con resultados como: "se logró comprender que el docente diseñador de portafolios pedagógicos va reconstituyendo su quehacer pedagógico en la medida en que va creando su obra" (Ñáñez-Rodríguez et al., 2019); lo anterior, haciendo referencia al proyecto sobre percepciones acerca de la pertinencia del uso de ambientes virtuales de aprendizaje en educación a distancia, para la formación inicial de docentes.

Lo anterior, soporta la relevancia del uso de las tecnologías de la información y comunicación (TIC) como parte de las competencias digitales docentes, lo cual va mucho más allá de la sola alfabetización digital (Falloon, 2020), y deja en evidencia la necesidad de estructurar un plan de formación que provea a los docentes de conocimientos, capacidades y herramientas, que les permita atender las exigencias que demandan las nuevas generaciones de educandos, tal como lo plantean Santos \& Serpa (2017), ofreciendo a los estudiantes un aprendizaje significativo, basado en la eficiencia y eficacia de la transmisión y gestión de información, y les permita la producción de nuevo conocimiento.

Sin embargo, frente a la inexistencia de directrices concretas sobre la formación digital docente, a nivel universitario, se abre la posibilidad de generar nuevas alternativas para la creación de planes y proyectos, en cada institución, en busca de fortalecer estas competencias y teniendo que "la formación permanente y desarrollo profesional, son tanto responsabilidad de los docentes como de las instituciones, en la medida que el mejoramiento de la educación es un asunto de corresponsabilidad" (Montoya y González (2019).

Soportados bajo la premisa que reza: el fortalecimiento de competencias digitales docentes y el uso de herramientas como mediadoras del proceso de aprendizaje, hacia una educación de calidad, se desarrolla, desde el 2019, la formulación de la propuesta institucional llamada: "Implementación de un programa de alfabetización digital aplicado a la didáctica educativa en los docentes de la facultad de Salud e Ingeniería y Ciencias Básicas" (Roa y Tovar, 2019), cuya 
primera fase se consolidó en la construcción de un instrumento y su aplicación a los docentes de la institución, con el objeto de realizar un diagnóstico de apropiación de las herramientas tecnológicas en el aula, en razón de lo expuesto.

Los resultados obtenidos en la primera fase son el insumo de la presente investigación, que integró tanto el análisis de estos como el rastreo bibliográfico de modelos de formación, teniendo como núcleo la propuesta realizada por el MEN (2013), del cual se extracta la categorización por niveles de apropiación, allí enunciados, como Explorador, Integrador e Innovador, y a su vez fraccionados cada uno en cinco competencias, catalogadas como: Pedagógica, Tecnológica, Investigativa, Gestión y Comunicativa.

Teniendo en cuenta, como propósito de la investigación, la construcción del plan de formación de competencias digitales, y dando continuidad y uso a la información obtenida de la primera fase del proyecto, se delineó la propuesta del curso estructurado bajo el concepto de microcurso, por nivel y por competencia, lo cual se encuentra inmerso dentro del enfoque pedagógico del aprendizaje basado en retos, permitiendo la generación de producciones de conocimiento, a partir de la puesta en contexto de una situación problémica (Observatorio de Innovación Educativa del Tecnológico de Monterrey, 2016), que implique desafío y reflexión para su resolución, y la cual debe abordarse con base en la integración de las TIC, logrando con ello direccionar y maximizar la apropiación de las herramientas digitales.

\section{Marco teórico}

\section{Competencias digitales en el marco internacional}

Las nuevas realidades constituyen nuevas sociedades, las cuales se envuelven dentro del valor del conocimiento, apalancadas por el acelerado auge de las tecnologías y su implicación en todos los contextos, exigiendo habilidad en su dominio; así las cosas, el campo educativo ahora, se identifica dentro de los lineamientos del Modelo pedagógico dialogante, que García y Fabila (2011) relacionan en sus dimensiones humanas, cognitiva, socio afectiva y práxica del aprendizaje, bajo conformación de competencias, destacando: el aprendizaje independiente interconectado y el uso estratégico de las TIC para fortalecer procesos cognitivos; de la misma manera, se extiende 
hacia el trabajo colaborativo y la comunicación, propios del aprendizaje en red, como enfoque de gestión de información, aunado al constructivismo en la era digital, sobre el cual se inscribe la presente investigación.

La inmersión de las nuevas tecnologías de la información y la comunicación en la sociedad, es un fenómeno de cambios que reorientan todos los ámbitos, y del cual se precisa reconocer, aceptar y adoptar, denotando para este estudio los que inciden directamente el marco educativo y que provocan una dinámica frente al cómo educar; es por ello que se incrementa la necesidad de establecer los lineamientos que deberá desarrollar el docente para llevar a cabo, de manera óptima, la consecución de los objetivos de aprendizaje normalizados del sistema educativo.

Lo anterior, deriva en procesos de estandarización en educación, como los relacionados por C. Hernández, Arévalo et al. (2016) en el Proyecto de la Organización para la Cooperación y el Desarrollo Económico de 1997, llamado Definición y Selección de Competencias (DeSeCo), cuyo objeto es el de evaluar la formación de los estudiantes mediante las pruebas Pisa (Programme for International Student Assessment), las cuales persiguen la identificación de determinadas capacidades, habilidades y aptitudes que, en conjunto, permiten a la persona resolver algún tipo de problemática.

A partir de los años noventa se exhibe, con mayor relevancia, el concepto de competencias, como habilidades y destrezas necesarias en los diferentes campos del saber, y que ahora se aúnan a las requeridas por el uso de las TIC, siendo el aula el espacio de promoción para el desarrollo y potenciación de estas, tanto en el desempeño académico como en la vida diaria. En este orden de ideas, son numerosos los estudios que han generado conceptualizaciones y posturas, dirigidas tanto a las competencias que debe adquirir el estudiante como a las que debe tener el docente, y de las cuales se presentan, a continuación.

Inicialmente, se parte de las conceptualizaciones dadas por teóricos como la figura del profesor ideal, fundamentado en el desarrollo de una ciudadanía adaptada al mundo contemporáneo, y de la construcción de competencias, saberes y posturas como práctica reflexiva e implicación crítica (Perrenaud, 2001); más adelante, se encuentra que Zabalza (2003) aborda principalmente lo referido a los retos que enfrenta la educación, entre los cuales incluye el modelo de formación basado en competencias, como el detonante en el cambio de formato universitario, el cual es excesivamente teórico, introduciendo los dogmas sobre los que parte la nueva enseñanza 
de asimilación de nuevos conocimientos y su uso o aplicación en la elaboración de productos; fijando su postura en la implicación del uso de nuevas tecnologías y su uso didáctico

Centrado el interés en la competencia digital que deben tener los docentes, se reconoce el modelo formulado por Mishra \& Koehler (2008), el cual presume la integración compleja del conocimiento disciplinar, pedagógico y tecnológico, esbozado en el modelo TPACK, donde el desarrollo docente es considerado base dentro de la enseñanza efectiva con tecnología. Igualmente relevante, son las valoraciones relacionadas por Domingo y Marqués (2011), quienes refieren la necesidad de una alfabetización que relacione las competencias digitales del docente con el uso y apropiación de las TIC, de manera previa y paralela a las que requieren todos los ciudadanos, para utilizarlas tanto en su quehacer personal como profesional.

Por otro lado, Vargas et al. (2014) recopilan y exponen algunas de las diferentes categorizaciones de las competencias digitales del docente, frente a la apropiación de TIC, dadas por diferentes autores que se exponen a continuación. El Ministerio de Educación de Chile (2006, como se citó en Vargas et al., 2014) define como competente al docente, en el uso de las TIC, cuyo dominio abarca cinco áreas, determinadas como: pedagógica, conocimiento de las TIC en la docencia, habilidades en la gestión escolar apoyada en TIC, uso de TIC para el desarrollo profesional docente, y conocimientos técnicos (p. 363). Por otro lado, Sabaliauskas, Bukantaité y Pukelis (2006, como se citó en Vargas et al., 2014), las categorizan como: básicas, tecnológicas, del área ética, de integración en la enseñanza, métodos didácticos, y gestión de procesos de enseñanza y aprendizaje (p. 363). Finalmente, Guzmán y Nussbaum (2009, como se citó en Vargas et al., 2014) proponen las competencias en instrumental-tecnológica, pedagógica-curricular, didáctica-metodológica, de evaluación-investigación, comunicacional-relacional y personalactitudinal (p. 364).

La incorporación de la competencia digital en el contexto educativo, corresponde a la necesidad que precede la transformación digital y su integración en la sociedad del conocimiento, surgiendo entonces como una de las competencia clave que el ser humano actual debe apropiar; es por ello que se ha convertido en uno de los pilares, tanto para el sistema educativo europeo como en el resto del mundo, señalando al docente como principal promotor de las habilidades necesarias, para el aprendizaje permanente, en sus educandos (Svensson \& Baelo, 2014) 
Después del recorrido sobre conceptualización, relevancia y categorización de las TIC, se puntualiza ahora en procesos que introducen lineamientos en TIC, con la intención de potenciar las capacidades cognitivas y desarrollo de destrezas en los docentes, mediante procesos de formación y actualización, hacia una cualificación, beneficiando el aprendizaje de estudiantes. Lo anterior, a partir del desarrollo de diversas iniciativas en el ámbito mundial, entre las que destacan C. Hernández, Arévalo et al. (2016): el Marco general de estándares para el uso de las TIC 20012002, en Australia; los estándares nacionales de tecnologías de información y comunicación para docentes (NETS-T), en Estados Unidos, entre otros, desprendiéndose por parte de UNESCO, el documento Estándares de competencias TIC para docentes en 2008, el cual profundiza su interés hacia el progreso social y económico del país.

Finalmente, en el marco de la observación y análisis de la temática, se abordan algunos estudios relevantes que, según los resultados obtenidos, toman en consideración el mayor nivel de dominio de competencias TIC, versus la edad o formación tecnológica previa.

Fernández y Fernández (2016) consideran una muestra de 1433 profesores, caracterizados en un $70 \%$ como generación X (nacidos entre 1966 y 1976), distribuidos en niveles de primaria, con un $53,73 \%$, un $42,78 \%$ de secundaria, y $3.49 \%$ los dos, categorizados bajo criterios de dominio de competencia en: nociones básicas, profundización del conocimiento y generación de conocimiento, arrojando que el 39,71 \% se sitúa en perfil medio, $36.85 \%$ malo y $9,56 \%$ muy malo, totalizando el $46,31 \%$ con perfil negativo en profesores de mayor edad, contrario a los de menor edad o con formación en ramas científico- tecnológica y/o TIC.

Por otro lado, expone igual relevancia el estudio de López et al. (2020) con 611 docentes preuniversitarios de diferentes centros educativos, estratos y comunidades; cuyo resultado visualiza una estrecha relación entre la edad docente y el nivel de competencia TIC, donde a menor edad, es más elevado su nivel de competencia digital.

También, se incluye el estudio de Guillén et al. (2020), el cual se realizó con una muestra de 108 estudiantes de docencia. El resultado evidenció una actitud negativa hacia el uso de las TIC, con una relación altamente dependiente entre las variables motivación y apropiación de competencia digital, excluyendo la influencia de la edad, dado el perfil de los participantes.

Tomando en cuenta lo anterior, cobra interés lo manifestado por McGarr \& McDonagh (2019), quienes recopilan resultados de diferentes estudios aplicados, los cuales exponen la 
relevancia de la concepción y actitud que debe reflejar el docente sobre el uso de las herramientas TIC en el aula, si le concibe como herramienta necesaria potenciadora de aprendizaje o amenaza de distracción dentro de la actividad educativa, dado que en la mayoría de las respuestas obtenidas, se inclinaban a una aceptación de uso en el plano personal, pero no en lo profesional y pedagógico, repercutiendo en la minimización de su eficiencia.

\section{Competencia digital docente en Colombia}

Después de una larga trayectoria de identificación de necesidades, según el contexto internacional implicado, en lo referente a las competencias digitales que el docente debe incorporar en su quehacer, emerge una estandarización, a partir de la cual Colombia incursiona formalmente con tres proyectos principales, como lo mencionan C. Hernández, Ayala et al. (2016), dados por el marco normatizado en los estándares de competencias en tecnología e informática para educación básica y media (MEN, 2008); más adelante, se pone en marcha la Ruta de Apropiación de TIC en el Desarrollo Profesional Docente, que converge en el documento, Competencias TIC para el desarrollo profesional docente (MEN, 2013); posteriormente, a través del Viceministerio de Educación Superior, en el Programa Nacional de Innovación Educativa con Uso de TIC, se da una guía de las competencias deseadas para el dominio de las TIC en la educación superior, delineando las pautas que cada institución proponga y acoja, teniendo en cuenta la autonomía universitaria.

De otro lado, se toma en cuenta que la responsabilidad del docente en la educación, no solo se enfoca en el dominio del área disciplinar, sino que involucra las diferentes competencias y habilidades del siglo XXI que necesitan los educandos, por lo que se relacionan a continuación investigaciones que perfilan el nivel actual de los docentes, frente a la apropiación de estas tecnologías y su uso en el aula.

Said et al. (2017) se apoyan en 1447 encuestas a docentes, para estudiar las habilidades de pensamiento mediadas por las TIC (HPTic), según las actividades que realizan, categorizadas como HPTic inferior, aplicadas en procesos de Recordar, Comprender, Aplicar; y HPTic superior, que integra las anteriores, potenciadas con procesos de Analizar, Evaluar, Crear. El mencionado estudio encontró, principalmente, que predomina el HPTic superior, en los docentes menores de 50 años, 
y según nivel disciplinar; el HPTic inferior predomina para docentes pertenecientes a ciencias de la educación.

Sánchez et al. (2018), por su parte, estudian el nivel de competencia digital docente mediante investigación con cerca de 6000 participantes de instituciones estatales de Colombia, pertenecientes a práctica en educación preescolar, básica y media, cuyos resultados evidencian que los mayores puntajes de nivel innovador (escala superior de competencia TIC) se encuentran en la región Caribe, tienen entre los 31 y 50 años, laboran en básica secundaria y media, se desempeñan en el área de tecnología e informática, y pertenecen al estatuto docente más reciente, resaltando su alcance, gracias al proceso formativo disciplinar y tecnológico continuo.

Finalmente, C. Hernández, Arévalo et al. (2016) exponen los distintos niveles y competencias, de acuerdo con los estándares del MEN, aplicados a una muestra de 255 docentes, evidenciando que el 59,2 \% se autoevalúan con un nivel entre competente y muy competente, en categoría tecnológica y pedagógica, en tanto la mayoría tiene formación continua y posgradual. De estos, el $22 \%$ está vinculado con las áreas de informática y las TIC; sin embargo, se observan resultados medios para competencia de gestión académica, y bajos en competencia comunicativa e investigativa.

\section{Competencias TIC para el desarrollo profesional docente - Modelo MEN (2013)}

Las TIC son un componente esencial de la transformación social que irrumpe en todos los entornos, de tal manera que ha impactado hasta el campo científico, el cual indica gran significancia en el desarrollo de la sociedad (Colás y De Pablos, 2012, como se citó en Colás Bravo et al., 2018); razón por la cual, el MEN busca fomentar nuevas estrategias que permitan integrar la formación docente, competencias y el uso de las tecnologías en su quehacer, así como métodos educativos de innovación e investigación educativa, optimizando sus prácticas y robusteciendo la calidad académica en la formación de los educandos, hacía la generación de líderes dentro de la comunidad educativa, capaces de enfrentar las problemáticas de la cotidianidad, por medio del uso de las TIC.

Las diferentes propuestas de estandarización de formación docente, concuerdan con el establecimiento de múltiples componentes según el grado de profundización del conocimiento, sobre los mismos, por parte de cada uno de los profesores; por tal motivo, el MEN (2013), en el 
documento: Competencias TIC para el desarrollo profesional docente, define cinco competencias (ver figura 1): i) Tecnológica: refiriéndose al conocimiento y uso de aparatos tecnológicos; ii) Pedagógica: señala el manejo de las TIC en los procesos de enseñanza y aprendizaje; iii) Comunicativa: considera la facultad para expresarse, contactar y relacionarse en espacios virtuales y audiovisuales, a través de diferentes medios; iv) De Gestión: comprende el uso de las TIC en la planeación, organización, administración y evaluación de los procesos educativos; y v) Investigativa: precisa la habilidad de manejar las TIC para la transformación y producción del saber.

Estas cinco competencias se manejan a través de tres niveles: i) Explorador: hace alusión al primer encuentro de los docentes con las herramientas tecnológicas, en cuanto a la implementación en su quehacer laboral; ii) Integrador: en este, los docentes ya son más sabedores y diestros en el uso y apropiación de las diferentes herramientas digitales; y iii) Innovador: el cual se diferencia porque no solo utiliza las tecnologías conocidas, sino que además motiva a los docentes a encontrar nuevas opciones de uso de estas, de manera que se permita la generación de nuevo conocimiento, haciendo que el proceso de enseñanza y aprendizaje sea una actividad atractiva, motivadora e inspiradora.

\section{Figura 1}

Pentágono de competencias

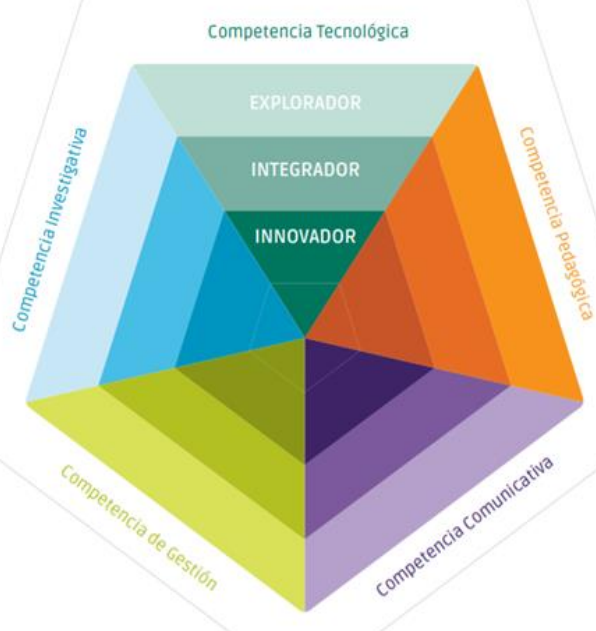

Nota: tomado de MEN (2013). 
El modelo expuesto ofrece pautas, criterios y parámetros que permiten a las instituciones asumirlo como insumo para la capacitación de toda la comunidad, frente al uso asertivo de las TIC, desde las diferentes competencias que, en conjunto y de acuerdo a los tres niveles, permiten como resultado generar saberes que den calidad a la educación, en cuanto a diseño, implementación y sostenibilidad de prácticas innovadoras, como valor agregado al diseño curricular propio de cada programa.

El grado de complejidad del modelo MEN (2013) se maneja en un amplio espectro, tipo espiral, iniciando por el explorador, seguido del nivel integrador y, finalmente, innovador. Al pasar por cada uno de estos, se muestra un nivel de manejo y dominio cada vez más significativo; es decir, van circulando de una etapa de generalidad a uno de mayor diferenciación. Cada una de las competencias anunciadas se pueden realizar de manera independiente, lo que indica que un docente puede estar en momentos diferentes de progreso en cada una de estas.

Para el caso de la competencia tecnológica, se tiene que, en el nivel Explorador, el docente se familiariza con diferentes tipos de herramientas digitales y tecnológicas, con el objeto de integrarlas paulatinamente a su práctica docente; en cuanto al nivel Integrador, el docente utiliza con un objetivo pedagógico diferentes herramientas tecnológicas en los procesos educativos, de acuerdo a su rol y área de formación, así como el contexto en el que se desempeña; y, finalmente, el docente en el nivel Innovador, aplica el conocimiento de una manera amplia con un uso variado de herramientas tecnológicas, las cuales implementa, con el fin de dar soluciones a problemas en un contexto específico.

En cuanto a la competencia pedagógica, el docente, en el nivel Explorador, reconoce nuevas estrategias y metodologías, moderadas por las TIC, como herramienta para su práctica profesional; en el nivel Integrador, se plantea proyectos y estrategias de aprendizaje con el uso de las TIC, en aras de potencializar el aprendizaje en sus estudiantes; y en un nivel Innovador, es capaz de liderar prácticas significativas que comprenden ambientes de aprendizaje innovadores, conforme a las necesidades de los estudiantes, todo ello enmarcado en un contexto específico.

Del mismo modo, la competencia comunicativa identifica el nivel Explorador, como aquél que emplea diferentes canales de comunicación y lenguaje, propios de las TIC, con el fin de comunicarse asertivamente con una comunidad específica; en el nivel Integrador, define estrategias 
de trabajo colaborativo, a partir de su cooperación en redes y comunidades, y hace uso de herramientas digitales que faciliten la socialización; finalmente, en un nivel Innovador, colabora en comunidades y pública producciones en diferentes medios digitales.

La competencia de gestión, por su parte, evalúa si el docente, en el nivel Explorador, es capaz de organizar actividades convenientes de su quehacer profesional y académico, apoyándose en el uso de herramientas TIC; en el nivel Integrador, se pretende que el docente tenga la capacidad de integrar las TIC en procesos de dinamización de las gestiones académicas - administrativas; y finalmente, en el nivel Innovador, debe ser capaz de proponer y liderar iniciativas para optimizar procesos en su gestión académica.

Finalmente, la competencia investigativa permite facilitar procesos de recolección de datos y científicos a través de las TIC; para iniciar en el nivel Explorador, se pretende el uso de herramientas digitales para hacer registro y seguimiento de lo que vive y observa en su práctica o un contexto específico; en el nivel Integrador, debe ser capaz de liderar proyectos de investigación, de su área de interés, con la participación de estudiantes; y en el nivel más alto, el Innovador, debe ser capaz de construir estrategias educativas innovadoras que incluyan la generación colectiva de nuevos conocimientos.

El proyecto derivado de esta investigación se direcciona como proceso institucional de cualificación docente, generando un plan de formación de competencias mínimas a adquirir con rutas flexibles, que sigue el curso de espiral del Modelo MEN (2013), obtenidas mediante microcursos dentro de una plataforma con interfaz amigable e intuitiva, a los cuales se accede previo resultado de una evaluación diagnóstica, que determina el módulo y el nivel de inicio; una vez el usuario (docente) ingresa, el panel de bienvenida presenta el entorno diseñado con instrucciones de recorrido y participación, así como los contenidos en formato textual y multimedial, que permiten la adquisición de conocimientos, concebidos bajo la metodología de desarrollo del reto, cuyo progreso se evalúa mediante la consecución de los objetivos de aprendizaje. 


\section{Metodología}

Para el desarrollo de la investigación se trabajó bajo un enfoque mixto, por medio del diseño de triangulación concurrente (DITRIAC), el cual se efectuó en dos fases:

\section{Primera fase: construcción y validación del instrumento}

Diseño de los instrumentos: este está compuesto por las cinco dimensiones del modelo Prendes et al. (2018): aspectos técnicos, información-comunicativa, educativo, analítico y socialética, donde se plantearon diferentes tipos de preguntas que fueron reduciéndose a 31, distribuidas en 2 secciones. La primera, consta de 22 preguntas, las cuales utilizaban una escala de Likert "Acuerdo" de 5 puntos, tecnificada y codificada como: Totalmente en desacuerdo (1), En desacuerdo (2), Indeciso (3), De acuerdo (4), y Totalmente de acuerdo (5); además, en la segunda sección se incluyeron 9 preguntas Likert de tipo "Frecuencia", donde la cuantificación más alta corresponde a Muy frecuentemente, y la más baja a Nunca. Es importante mencionar que el instrumento fue sometido a un panel de expertos, por medio del método Delphi, donde se realizaron los ajustes pertinentes a las preguntas, de acuerdo con su percepción.

\section{Segunda fase: análisis de los datos}

Una vez diseñado el instrumento, se aplicó a una muestra de 174 docentes de las Facultades de Salud e Ingeniería y Ciencias Básicas de la sede de Bogotá, este muestreo fue de tipo incidental no probabilístico a un grupo de docentes; para el estudio de los datos, se realizó un análisis factorial, partiendo de los principios de Kaiser (1974), mediante las pruebas estadísticas de Kaiser-MeyerOlkin (KMO) y la prueba de esfericidad de Bartlett (BTS), la cual garantiza que las características de los datos obtenidos en la muestra son los adecuados para dicho análisis; seguido, se realizó un análisis factorial exploratorio; $\mathrm{y}$, finalmente, se desarrolló un análisis factorial confirmatorio.

Del análisis de los datos cuantitativos y cualitativos se realizó una triangulación concurrente, teniendo en cuenta el diseño DITRIAC (R. Hernández et al., 2014), y con base en los modelos de Prendes et al. (2018) y del MEN (2013). En consecuencia, se pudo determinar un plan 
de formación que abarcara cada una de las competencias y los niveles en que se encuentra el docente.

\section{Resultados}

\section{Construcción y validación del instrumento}

Para el análisis de cada uno de los factores se utilizó el software Statistical Product and Service Solutions (SPSS) y se ejecutó la prueba de Kaiser-Meyer-Olkin (KMO) y la prueba de esfericidad de Bartlett (BTS), con el fin de garantizar que las particularidades de los datos proporcionados de la muestra fueran los adecuados para el análisis factorial exploratorio, teniendo en cuenta lo expuesto por Kaiser (1974).

\section{Tabla 1}

Prueba de KMO y Bartlett

\begin{tabular}{llr}
\hline Medida Kaiser-Meyer-Olkin de adecuación de muestreo &, 928 \\
\hline & Aprox. Chi-cuadrado & 3883,800 \\
\cline { 2 - 3 } $\begin{array}{l}\text { Prueba de esfericidad de } \\
\text { Bartlett }\end{array}$ & Gl & 435 \\
\cline { 2 - 3 } & Sig. &, 000 \\
\hline
\end{tabular}

Nota: Elaboración propia, a partir de los datos recolectados y analizados en SPSS.

Se realizó la prueba de adecuación muestral KMO, donde se analizó el resultado, teniendo como base lo expuesto por Morales y Medina (2015), quienes refieren que esta medida debe tomar valores entre 0 y 1 , y entre mayor sea su valor, demuestra que el análisis factorial es más adecuado. Puntualizando el estudio, en la tabla 1 es posible observar que la prueba Kaiser-Meyer-Olkin es de 0.928, siendo una excelente adecuación muestral, según lo establecido por Kaiser (1974).

Otra prueba a la que se expuso el instrumento de medición fue la prueba de esfericidad de Bartlett (Tabla 1), donde se observó un Aprox. Chi-cuadrado de 3883,800 y un Sig. De 0.000; con lo cual se puede exponer que las variables quedan bien declaradas a través de los componentes 
extraídos, ya que, en primera instancia, todos los valores de KMO, en cada una de las dimensiones, son mayores a 0.5; además, que el grado de significancia adquirido en la prueba de Bartlett es menor que 0.05 ; por tanto, se estima como válido.

De lo anterior, se procedió a realizar un análisis factorial, por medio de la matriz antiimagen, específicamente la correlación, donde se pudo determinar que la diagonal de la correlación anti-imagen de las preguntas del cuestionario es de 0.903; por ende, no se extrae ninguna variable del instrumento. Seguido, se analizó la matriz de componente rotativo (tabla 2), dando como resultado que, de los cinco factores planteados inicialmente, estos se agrupaban en tres (tabla 3), de allí que se renombrarlos según la finalidad conjunta de las preguntas, respectivamente: 1. Uso e impacto social de las TIC; 2. Diseño, Gestión y Evaluación de las TIC; y 3. Análisis e Integración de las TIC en la Formación.

\section{Tabla 2}

Matriz de componente rotado

\begin{tabular}{|c|c|c|c|c|}
\hline & \multicolumn{4}{|c|}{ Componente } \\
\hline & 1 & 2 & 3 & 4 \\
\hline $\begin{array}{l}\text { Diseño, creo y modifico diferentes formatos con algún programa } \\
\text { informático (Word, Excel, PowerPoint, entre otros). }\end{array}$ & ,638 &, 102 & ,292 &, 130 \\
\hline $\begin{array}{l}\text { Diseño, creo y modifico diferentes formatos con herramientas } \\
\text { web } 2.0 \text {, como, por ejemplo: blogs, wiki, Second life, podcasts, } \\
\text { RSS feed reader, flicker, edublog. }\end{array}$ & ,291 & ,466 & 307 &,- 009 \\
\hline $\begin{array}{l}\text { Utilizo correctamente las plataformas de enseñanza virtual; como, } \\
\text { por ejemplo: Canvas, Blackboard, Moodle, Edmodo, Google } \\
\text { Classroom, Classdojo, entre otras. }\end{array}$ & ,642 &, 324 & ,397 &,- 075 \\
\hline $\begin{array}{l}\text { Conozco herramientas apoyadas con internet que permiten el } \\
\text { trabajo colaborativo, como, por ejemplo, trabajo en: wiki, Google } \\
\text { Drive, One Drive, Teams, Planner, Google Classroom, Edmodo, } \\
\text { Creately, Goconqr, blogs, Foros, encuentros sincrónicos. }\end{array}$ &, 763 & ,207 & ,315 &, 158 \\
\hline $\begin{array}{l}\text { Utilizo recursos de la web } 2.0 \text { como, por ejemplo: Youtube, } \\
\text { agregadores sociales, wikis, blogs, aplicaciones en línea, con el } \\
\text { ánimo del desarrollo de actividades o evaluaciones en clase (Por } \\
\text { ejemplo: Genially, Kahhot, Quizzez, Mindomo, Animoto, } \\
\text { Filmora, Wix). }\end{array}$ & ,641 &, 342 &, 146 &, 150 \\
\hline
\end{tabular}


Uso bases de datos o buscadores especializados (EBSCO, proquest, SCOPUS) para el desarrollo del contenido de las asignaturas que imparto.

,726 ,097 ,012

, 335

Hago uso de las redes sociales como apoyo a la apropiación de conceptos; como, por ejemplo: Second life, Twitter, Facebook, Instagram, Linkedin, Pinterest, Skype, WhatsApp.

Utilizo estudios de casos con ayuda de las TIC para la formación de mis alumnos.

,587 246 , 246 $\quad, 140$

Con el uso de herramientas informáticas he notado que el rendimiento académico de los estudiantes ha mejorado.

244 , 230 , , 511 $\quad, 68$

Tengo habilidades en el manejo de las TIC dentro del aula de clase.

,730 248 ,380

, 001

Tengo confianza al emplear los medios tecnológicos frente al grupo de estudiantes.

,819 , 192 ,334 $\quad-, 070$

He recibido formación en el uso de las TIC a lo largo de mi trayectoria docente.

,661 $\quad 325 \quad 289 \quad-, 069$

Considero que el uso de las TIC en clase es un factor determinante en el aprendizaje de los estudiantes.

,313 , 120 ,846 $\quad-, 016$

Considero que el uso de las TIC en clase es una herramienta alternativa para la enseñanza de los diversos contenidos.

,518 $\quad-, 021 \quad, 635 \quad, 135$

Considero que el uso de las TIC en clase es una herramienta totalmente necesaria.

$\begin{array}{llll}, 161 \quad, 892 & , 002\end{array}$

Considero que el uso de las TIC en clase es una alternativa que no necesariamente influye en el aprendizaje de los estudiantes.

$\begin{array}{llll}, 117 \quad 040 \quad, 062 & , 795\end{array}$

Considero que el uso de las TIC en clase facilita el trabajo en grupo, la colaboración y la inclusión con los estudiantes.

, 350

, 165 , 767

, 153

Considero que el uso de herramientas virtuales permite optimizar tiempo y esfuerzo.

,416 ,095 ,778 ,036

Uso redes sociales como Researchgate y academia.edu para estar informado de los avances en mi disciplina.

,289 , 353 234

Conozco el impacto que tiene la implementación de las TIC en el aula, así como en la sociedad.

, 140

, 528

, 064

Conozco el impacto ético del uso de las TIC en diversos estamentos sociales. 
Propició la búsqueda de información fuera del aula con otros medios digitales, como apoyo a la gestión académica.

,308 $\quad, 580 \quad, 013 \quad, 154$

Hago uso de herramientas de comunicación sincrónica (por ejemplo: Skype, Hangouts, Collaborate, Zoom, chat) y asincrónica (por ejemplo: foros, wiki, correo, blogs, edublogs) , 154 ,739 , 134 $-, 212$ para interactuar con los estudiantes.

Abordo tecnologías (simuladores, software especializado, entre otros) para suplir necesidades educativas identificadas en el grupo de estudiantes.

Diseño actividades on-line que complementan o apoyan los procesos de enseñanza y aprendizaje presenciales, como, por ejemplo: Educaplay, Genially, Canva, Animoto, Vizia, Vismeo, ,092 , 795 ,077 , 129 Blogger, Tumblr, Wix, entre otros).

Motivo el trabajo colaborativo a través de herramientas de comunicación sincrónica, como: Blackboard Collaborate, Hangouts, Skype, Adobe Connect; y asincrónicas, por medio de: correo electrónico, wikis, Google Drive, entre otros.

Ayudo a los estudiantes a gestionar y procesar la información de manera más eficaz, utilizando herramientas informáticas.

Propongo en mis clases proyectos de aula que propicien el desarrollo de competencias digitales por parte de los estudiantes.

,252 , , 008

Empleo encuestas o cuestionarios como apoyo en el desarrollo de mis clases, haciendo uso de herramientas como formularios Google Drive, Kahoot, Quizizz, entre otros.

, 100 , , , , 047 $\quad, 08$

Hago uso de aplicaciones móviles como apoyo al abordaje de algún concepto o temática en mis clases presenciales.

, 075

, 725

, 217 , 178

Método de extracción: análisis de componentes principales.

Método de rotación: Varimax con normalización Kaiser. ${ }^{a}$

a. La rotación ha convergido en 6 iteraciones.

Nota: Elaboración propia, a partir de los datos recolectados y analizados en SPSS. 


\section{Tabla 3}

Ítems del instrumento por dimensión

\begin{tabular}{|c|c|c|}
\hline Categoría & $\begin{array}{l}\text { Codificación } \\
\text { por Dimensión }\end{array}$ & Ítem \\
\hline \multirow{11}{*}{$\begin{array}{l}\text { Uso e impacto social } \\
\text { de las TIC }\end{array}$} & $\mathrm{T} 1$ & $\begin{array}{l}\text { Diseño, creo y modifico diferentes formatos con algún programa } \\
\text { informático (Word, Excel, PowerPoint, entre otros). }\end{array}$ \\
\hline & E1 & $\begin{array}{l}\text { Diseño, creo y modifico diferentes formatos con herramientas web } 2.0 \text {, } \\
\text { como, por ejemplo: blogs, wiki, Second life, podcasts, RSS feed reader, } \\
\text { flicker, edublog. }\end{array}$ \\
\hline & I1 & $\begin{array}{l}\text { Utilizo correctamente las plataformas de enseñanza virtual; como, por } \\
\text { ejemplo: Canvas, Blackboard, Moodle, Edmodo, Google Classroom, } \\
\text { Classdojo, entre otras. }\end{array}$ \\
\hline & $\mathrm{T} 3$ & $\begin{array}{l}\text { Conozco herramientas apoyadas con internet que permiten el trabajo } \\
\text { colaborativo, como, por ejemplo, trabajo en: wiki, Google Drive, One } \\
\text { Drive, Teams, Planner, Google Classroom, Edmodo, Creately, Goconqr, } \\
\text { blogs, Foros, encuentros sincrónicos. }\end{array}$ \\
\hline & I2 & $\begin{array}{l}\text { Utilizo recursos de la web } 2.0 \text { como, por ejemplo: Youtube, agregadores } \\
\text { sociales, wikis, blogs, aplicaciones en línea, con el ánimo del desarrollo } \\
\text { de actividades o evaluaciones en clase (Por ejemplo: Genially, Kahhot, } \\
\text { Quizzez, Mindomo, Animoto, Filmora, Wix) }\end{array}$ \\
\hline & $\mathrm{S} 1$ & $\begin{array}{l}\text { Uso bases de datos o buscadores especializados (EBSCO, proquest, } \\
\text { SCOPUS) para el desarrollo del contenido de las asignaturas que } \\
\text { imparto. }\end{array}$ \\
\hline & $\mathrm{T} 4$ & $\begin{array}{l}\text { Hago uso de las redes sociales como apoyo a la apropiación de } \\
\text { conceptos; como, por ejemplo: Second life, Twitter, Facebook, } \\
\text { Instagram, Linkedin, Pinterest, Skype, WhatsApp. }\end{array}$ \\
\hline & T5 & $\begin{array}{l}\text { Utilizó estudios de casos con la mediación de las TIC para la formación } \\
\text { de mis alumnos. }\end{array}$ \\
\hline & A2 & $\begin{array}{l}\text { Con el uso de herramientas informáticas he notado que el rendimiento } \\
\text { académico de los estudiantes ha mejorado. }\end{array}$ \\
\hline & S4 & Tengo habilidades en el manejo de las TIC dentro del aula de clase. \\
\hline & S5 & $\begin{array}{l}\text { Tengo confianza al utilizar los medios tecnológicos frente al grupo de } \\
\text { estudiantes. }\end{array}$ \\
\hline \multirow{2}{*}{$\begin{array}{l}\text { Diseño, Gestión y } \\
\text { Evaluación de las TIC }\end{array}$} & $\mathrm{T} 2$ & $\begin{array}{l}\text { He recibido formación en el uso de las TIC a lo largo de mi labor } \\
\text { docente. }\end{array}$ \\
\hline & $\mathrm{E} 4$ & $\begin{array}{l}\text { Considero que el uso de las TIC en clase es un factor concluyente en el } \\
\text { aprendizaje de los estudiantes. }\end{array}$ \\
\hline
\end{tabular}




\begin{tabular}{|c|c|c|}
\hline & E5 & $\begin{array}{l}\text { Considero que el uso de las TIC en clase es una herramienta alternativa } \\
\text { para la enseñanza de los diversos contenidos. }\end{array}$ \\
\hline & E6 & $\begin{array}{l}\text { Considero que el uso de las TIC en clase es una herramienta totalmente } \\
\text { necesaria. }\end{array}$ \\
\hline & E7 & $\begin{array}{l}\text { Considero que el uso de las TIC en clase es una opción que no } \\
\text { necesariamente interviene en el aprendizaje de los estudiantes. }\end{array}$ \\
\hline & I3 & $\begin{array}{l}\text { Considero que el uso de las TIC en clase facilita el trabajo en grupo, la } \\
\text { colaboración y la inclusión con los estudiantes. }\end{array}$ \\
\hline & I4 & $\begin{array}{l}\text { Considero que el uso de herramientas virtuales permite optimizar tiempo } \\
\text { y esfuerzo. }\end{array}$ \\
\hline & E8 & $\begin{array}{l}\text { Uso redes sociales como Researchgate y academia.edu para estar } \\
\text { informado de los avances en mi disciplina. }\end{array}$ \\
\hline & E9 & $\begin{array}{l}\text { Conozco el impacto que tiene la implementación de las TIC en el aula, } \\
\text { así como en la sociedad. }\end{array}$ \\
\hline & E10 & $\begin{array}{l}\text { Conozco el impacto ético del uso de las TIC en diversos estamentos } \\
\text { sociales. }\end{array}$ \\
\hline \multirow{6}{*}{$\begin{array}{l}\text { Análisis e Integración } \\
\text { de las TIC en la } \\
\text { Formación }\end{array}$} & E2 & $\begin{array}{l}\text { Propició la búsqueda de información fuera del aula con otros medios } \\
\text { digitales como apoyo a la gestión académica. }\end{array}$ \\
\hline & $\mathrm{S} 2$ & $\begin{array}{l}\text { Hago uso de herramientas de comunicación sincrónica (por ejemplo: } \\
\text { Skype, Hangouts, Collaborate, Zoom, chat); y asincrónica (por ejemplo: } \\
\text { foros, wiki, correo, blogs, edublogs) para interactuar con los estudiantes. }\end{array}$ \\
\hline & E3 & $\begin{array}{l}\text { Abordo tecnologías (simuladores, software especializado, entre otros) } \\
\text { para suplir necesidades educativas identificadas en el grupo de } \\
\text { estudiantes. }\end{array}$ \\
\hline & A3 & $\begin{array}{l}\text { Diseño actividades on-line que complementan o apoyan los procesos de } \\
\text { enseñanza y aprendizaje presenciales, como, por ejemplo: Educaplay, } \\
\text { Genially, Canva, Animoto, Vizia, Vimeo, Blogger, Tumblr, Wix, entre } \\
\text { otros). }\end{array}$ \\
\hline & S3 & $\begin{array}{l}\text { Motivo el trabajo colaborativo a través de herramientas de comunicación } \\
\text { sincrónica, como: Blackboard Collaborate, Hangouts, Skype, Adobe } \\
\text { Connect; y asincrónicas, por medio de: correo electrónico, wikis, } \\
\text { Google Drive, entre otros. }\end{array}$ \\
\hline & A5 & $\begin{array}{l}\text { Ayudo a los estudiantes a gestionar y procesar la información de manera } \\
\text { más eficaz utilizando herramientas informáticas. }\end{array}$ \\
\hline
\end{tabular}

Nota: Elaboración propia.

Para evaluar la confiabilidad del instrumento de medición, se crearon variables resumidas para el análisis de datos, con las cuales se realizó un análisis de consistencia interna, mediante el 
alfa de Cronbach. Su interpretación, según Morales y Medina (2015), es que cuanto más se aproxime el índice al extremo 1, mejor es la confiabilidad (100\%), fundamentando un resultado aceptable a partir de 0.70; en ese sentido, se aplicó el análisis de fiabilidad para los cuatro factores.

Este arrojó como resultado que los primeros tres factores tienen un alfa aceptable (factor 1, es de 0,937; factor 2, es de 0,892; y el factor 3, es de 0,904); excepto el factor 4, con 0.328, el cual se debió eliminar del instrumento, por lo cual es aceptable y, por ende, confiable; de igual forma, tiene un alto grado de confiabilidad, validando su uso para la recopilación de datos, dando como resultado un instrumentos con tres dimensiones: uso e impacto social de las TIC; diseño, gestión y evaluación de las TIC; y análisis e integración de las TIC en la formación, con 27 ítems (tabla 4).

\section{Tabla 4}

Estadísticas de fiabilidad de los factores

\begin{tabular}{ccl}
\hline Factor & Alfa de Cronbach & \multicolumn{1}{c}{ Preguntas } \\
\hline 1 & .937 & T1, T3, T4, T5, S1, S4, S5, I1, I2, E1, A2 \\
\hline 2 & .892 & E4, E5, E6, E7, E8, E9, E10, I3, I4, T2 \\
\hline 3 & .904 & E2, E3, S2, S3, A3, A5 \\
\hline 4 & .328 & A4, I2 \\
\hline
\end{tabular}

Nota: Elaboración propia

\section{Triangulación de los datos}

Teniendo en cuenta el objetivo planteado en la investigación, se seleccionó la técnica de "triangulación múltiple", donde confluye la unión de dos tipos de triangulación, como lo son la de fuentes de datos y la de investigador; esto debido al uso mixto de técnicas cuantitativas y cualitativas, de recogida y análisis de datos, y, por otro lado, desde la triangulación de investigador, teniendo en cuenta las diferentes perspectivas de los investigadores del proyecto, los cuales enriquecieron el proceso de investigación, tanto en la etapa de recolección de datos como en la de análisis de los mismos, lo cual disminuye los sesgos que puede producir una única mirada, concediendo a los resultados obtenidos una mayor relevancia y fiabilidad. 
La implementación de las técnicas cualitativas aportó información particularizada y no mediada acerca de la realidad, en cuanto al aprovechamiento y uso pertinente de las tecnologías de la información y la comunicación, por parte de los docentes en sus aulas de clase. Esta información permitió contar con un marco del cual extraer los principales ejes temáticos y problemas, con el fin de generar propuestas de estrategias de mejoramiento y mejores prácticas, y de esta forma implementar un plan de formación integral que dé respuesta a las falencias identificadas.

Por consiguiente, la investigación cualitativa, junto con la revisión bibliográfica, sirvió como fase exploratoria de la investigación, permitiendo la manifestación de los aspectos más relevantes de la temática estudiada, que corresponde al uso y apropiación de las herramientas tecnológicas, por parte de los docentes de las facultades de Salud e Ingeniería y Ciencias Básicas. No obstante, los resultados obtenidos de la fase cualitativa también jugaron un papel fundamental en el proceso de análisis de los datos cuantitativos, ya que aportaron información relevante para explicar muchas de las relaciones observadas en las respuestas a los cuestionarios.

En cuanto a las técnicas cuantitativas, estas se fundamentan en los datos obtenidos, a través de encuesta, a una muestra no probabilística de 174 docentes, de las facultades de Salud e Ingeniería y Ciencias Básicas, lo cual facilita caracterizar a una población, en función de las variables; permitiendo, junto con las técnicas cualitativas, explicar lo que se pretende es medir.

Una vez cuantificados y evaluados los resultados de la encuesta, se observó que 90 docentes, correspondientes al $52 \%$ de la población, es de género femenino; y el $48 \%$ restante son masculinos (84 docentes); igualmente, se identificó que, de los 174 docentes encuestados, el $51 \%$ se encuentra en la generación Millennials, el $38 \%$ en la generación X, el 7 \% en la generación Baby boomers, y el $4 \%$ no da los datos correspondientes a su ubicación, en su nivel generacional.

Por otra parte, se pudo establecer un relacionamiento directo entre las competencias definidas por el modelo Prendes et al. (2018), y las competencias definidas por el modelo propuesto por el MEN (2013), ya que los dos clasifican sus competencias en 5 grandes grupos, los cuales cuentan con aspectos muy similares en su caracterización. De esta forma, las competencias: Social y Ética, Analítica, Educativa, Informacional/comunicativa, y Técnica, del modelo Prendes et al. (2018), se asocian correspondientemente con las competencias: Gestión, Investigativa, Pedagógica, Comunicativa y Tecnológica, del modelo MEN (2013), teniendo en cuenta el grado de similitud existente en los conocimientos, habilidades, comprensiones y disposiciones cognitivas, 
socioafectivas y psicomotoras, que se busca desarrollar y fortalecer en los docentes en cada uno de los modelos.

De igual forma, ambos modelos proponen clasificar el nivel de conocimiento y experticia que poseen los docentes, en cada una de las 5 competencias, en tres grandes grupos: Dominio Nivel 1, Dominio Nivel 2 y Dominio Nivel 3, según Prendes et al. (2018); y de forma equivalente, el MEN (2013) propone los niveles: Explorador, Integrador e Innovador.

Como se mencionó anteriormente, cada competencia tiene asociadas un grupo de preguntas en el instrumento validado, de la siguiente forma (Modelo MEN vs Modelo validado (Roa y Tovar, 2019)): competencia tecnológica: T1, E1, I2, S4 y S5; Competencias pedagógicas: I1, T4, E5, E2, S2, E3, A3; Competencia comunicativa: T5, E4, I3, E9, E10; Competencia de gestión: T3, S1, E8, S3, A5; Competencia investigativa: A2, T2, E6, E7, I4.

Adicionalmente, para realizar la clasificación de cada docente, frente al nivel de conocimiento en cada una de las competencias, se utilizaron las respuestas dadas por cada uno de ellos en las diferentes preguntas del cuestionario, y se asignaron puntajes de la siguiente forma: para las preguntas donde se consultaba qué tan de acuerdo estaba con un tema, los puntajes asociados a las respuestas fueron: Totalmente en desacuerdo (1), En desacuerdo (2), Indeciso (3); De acuerdo (4), y Totalmente en de acuerdo (5).

De forma similar se realizó para las preguntas de frecuencia, en las cuales se asignaron los siguientes valores, de acuerdo con las respuestas: Nunca (1), Raramente (2), Ocasionalmente (3), Frecuentemente (4), y Muy Frecuentemente (5). Consecutivamente, se calculó el promedio de las respuestas por cada grupo de preguntas, asociadas a cada competencia; y para determinar el nivel, se evaluó utilizando el siguiente parámetro: de 1 a 2,9, se le categorizó en el nivel Explorador; de 3 a 4,5, se clasificó como Integrador; y, finalmente, el docente que obtuvo más de 4,5 en una competencia, se le clasificó en nivel Innovador, en esa competencia. En los datos arrojados de la autoevaluación para los 174 encuestados, según el nivel, se observó que, en Integrador se encuentran 134 docentes, correspondiente al 77,01 \% de la muestra; el restante, se ubica como $11,49 \%$ en Explorador, y 11,49 \% en Innovador (ver figura 2). 


\section{Figura 2}

Caracterización de la población según nivel de autoevaluación

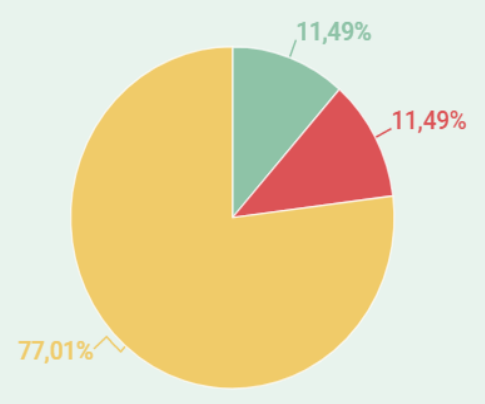

Nota: Elaboración propia.

En cuanto a la clasificación por competencias, se denota la competencia pedagógica, con valores de 69,54\% integrador, 19,54\% explorador y 10,92\% innovador; seguido de la competencia tecnológica, con 67,2 \% integrador, 21,3\% innovador y 11,5\% explorador; posteriormente, la competencia investigativa con 78,7 \% integrador, 12,1\% innovador y 9,2\% explorador; se continúa con la competencia comunicativa, con 70,1\% integrador, $16,7 \%$ explorador y 13,2 \% innovador; y finaliza la competencia social, con 59,2 \% integrador, 32,2 \% innovador y $8,6 \%$ explorador.

Lo anterior, permitió el diseño del programa de formación digital, el cual se planteó según los estándares del Ministerio de Educación Nacional, y cuyo objetivo fue capacitar a los docentes de la Fundación Universitaria del Área Andina, sede Bogotá, en aras de mejorar en la inclusión de las tecnologías y herramientas digitales dentro y fuera del aula; esto con el ánimo de contribuir a una mejora en los resultados de las pruebas de Estado y en los estándares de calidad.

El mencionado plan comprendió los tres niveles de formación y sus respectivas competencias, como lo expone el Modelo del MEN (2013). Además, aquel docente que se ubicó en el nivel más bajo deberá tomar los 15 módulos que se plantean. Cada uno de los módulos está propuesto para desarrollarse en cuatro semanas, de la siguiente manera: Semana 1: pretest, información del curso, contextualización y problematización; Semana 2: planteamiento del reto y 
herramientas para el apoyo de la solución del reto; Semana 3: presentación de la propuesta e informe de resultados; y Semana 4: evaluación, retroalimentación y postest.

Cabe acotar que lo más importante, durante el desarrollo del módulo, es la integración y experiencia de las herramientas digitales y tecnológicas, al alcance de los objetivos y resultados propuestos en cada situación de aprendizaje.

En la tabla 5 se presentan las diferentes temáticas a trabajar, por cada uno de los niveles y competencias, teniendo en cuenta el Pentágono (figura 1) del modelo MEN (2013), en cuanto a las subcompetencias que debe cumplir cada uno de los docentes.

\section{Tabla 5}

Temáticas por nivel y competencia

\begin{tabular}{|c|c|c|c|}
\hline & \multicolumn{3}{|c|}{ Niveles } \\
\hline Competencia & Exploración & Integrador & Innovación \\
\hline Tecnológica & $\begin{array}{l}\text { Uso y manejo de documentos } \\
\text { en la nube, prácticas virtuales. } \\
\text { Identificación, localización, } \\
\text { organización y análisis de la } \\
\text { información digital. } \\
\text { Herramientas digitales y } \\
\text { tecnológicas. }\end{array}$ & $\begin{array}{l}\text { Espacios virtuales de } \\
\text { aprendizaje, como páginas, } \\
\text { aplicaciones, plataformas } \\
\text { virtuales. }\end{array}$ & $\begin{array}{l}\text { Uso de simuladores e } \\
\text { inmersión a temas de } \\
\text { inteligencia artificial/ } \\
\text { Tecnologías inmersivas. }\end{array}$ \\
\hline Comunicativa & $\begin{array}{l}\text { Comunicación en entornos } \\
\text { digitales, compartir recursos a } \\
\text { través de herramientas en línea, } \\
\text { conectar y colaborar con otros } \\
\text { a través de herramientas } \\
\text { digitales, interactuar y } \\
\text { participar en comunidades y } \\
\text { redes; conciencia intercultural. } \\
\text { Uso de herramientas } \\
\text { sincrónicas/asincrónicas en } \\
\text { ambientes de aprendizaje } \\
\text { "TIGRE" }\end{array}$ & $\begin{array}{l}\text { Elaboración de productos } \\
\text { educativos en colaboración } \\
\text { con otros docentes y con } \\
\text { sus estudiantes, utilizando } \\
\text { varias herramientas a } \\
\text { través de canales digitales. } \\
\text { Creación de su identidad } \\
\text { digital y rastreamiento de } \\
\text { su huella digital. }\end{array}$ & $\begin{array}{l}\text { Uso de la tecnología para } \\
\text { comunicar ideas: apps, } \\
\text { página web, redes } \\
\text { sociales. } \\
\text { Colaboración mediante } \\
\text { canales digitales. }\end{array}$ \\
\hline Investigación & $\begin{array}{l}\text { Identificación de } \\
\text { problemáticas y soluciones a } \\
\text { través de las TIC con el uso } \\
\text { efectivo de bases de datos y la }\end{array}$ & $\begin{array}{l}\text { Construcción de } \\
\text { instrumentos de medición a } \\
\text { través de herramientas } \\
\text { digitales para gestionar }\end{array}$ & $\begin{array}{l}\text { Propuestas digitales de } \\
\text { investigación. } \\
\text { Desarrolla proyectos } \\
\text { educativos destinados a }\end{array}$ \\
\hline
\end{tabular}


gestión de la información en la red.

Utilización de repositorios y/o bibliotecas de recursos $\mathrm{y}$ materiales en la red, tanto de propósito general como educativo. información que permita ser analizada.

Desarrollo de actividades destinadas a formar $y$ concienciar al estudiante en el respeto hacia los derechos de autor de los contenidos distribuidos en Internet.

\begin{tabular}{|c|c|c|c|}
\hline Pedagógica & $\begin{array}{l}\text { Retroalimentación a través de } \\
\text { herramientas digitales como, } \\
\text { por ejemplo, Rubrics, Turnitin. }\end{array}$ & $\begin{array}{l}\text { Entornos virtuales de } \\
\text { aprendizaje y las } \\
\text { integraciones con otras } \\
\text { herramientas digitales, } \\
\text { apoyados en el aprendizaje } \\
\text { significativo. }\end{array}$ & $\begin{array}{l}\text { Aprendizaje para toda la } \\
\text { vida. } \\
\text { Aprendizaje vivencial. }\end{array}$ \\
\hline
\end{tabular}

Gestión de herramientas digitales colaborativas, como lo son: Google Classroom, Calendar.
Trabajo en plataformas: estrategias de retención. Gestión de contenidos a través de las TIC.

Crea materiales didácticos digitales en línea en una amplia gama de formatos y los publica en espacios digitales muy variados.
Uso de la inteligencia artificial en la vida cotidiana y en el aula.

Protección de información y datos personales, protección de la identidad digital, de los contenidos digitales, medidas de seguridad, uso responsable y seguro.

Nota: Elaboración propia.

El enfoque de enseñanza que se trabajó es el aprendizaje basado en retos, como respuesta a la planificación, desarrollo y evaluación de necesidades o problemáticas, a las que se puedan enfrentar los docentes en su quehacer diario. Así las cosas, al docente se le entregará una problemática de la cual debía identificar posibles soluciones, haciendo uso de las diferentes herramientas digitales expuestas en el nivel y competencia abordado; permitiendo abarcar las problemáticas de las aulas actuales, en aras de transformarlas en espacios más productivos. Es así como, con el desarrollo y avance de los módulos cursados, los retos se irán ampliando en duración y complejidad, avanzando en forma gradual en el enfoque basado en retos, como objetivo de perfeccionamiento y modelamiento, hacia una solución completa y aplicable en su entorno real. 


\section{Discusión}

A partir de los hallazgos encontrados, mediante la aplicación del instrumento en la institución universitaria, se observó la muestra de 174 docentes profesionales disciplinares y algunos posgraduales, fraccionados en el $52 \%$ mujeres y el restante hombres; exhibiendo, además, una caracterización generacional predominante con el 51 \% en Millenials, y el 38 \% generación X, cuyas edades oscilan entre 25 y 60 años.

Por otro lado, al revisar el nivel de clasificación que corresponde a la experticia de su práctica personal y docente, versus su etapa generacional, la cual, dada la caracterización, estaría enmarcada dentro de los rangos correspondientes a la generación $\mathrm{X}$, reconocidos como transicionales, quienes con empeño y disciplina logran posicionarse dentro de los llamados Inmigrantes digitales, aunados a los Millennials, propiamente consolidados como nativos digitales (Salas, 2019).

La competencia autoevaluada en el estudio para habilidades, dominio de ambiente y herramienta en el entorno digital, arrojó que un $77 \%$ de los docentes encuestados se encuentra dentro del nivel Integrador, en la totalidad de las competencias, especialmente en lo referido a la investigativa, dando cuenta de la relación de su formación posgradual y la profundización de su práctica profesional docente; el $12 \%$ se posiciona en el nivel Explorador, denotando un favorable bajo porcentaje en nivel inicial, lo cual orienta su compromiso, especialmente con las habilidades desarrolladas en la competencia Comunicativa; y el 11 \% en el más alto grado de la escala está, el Nivel Innovador, principalmente hacia las competencias sociales.

Lo anterior, es de suma relevancia si se relaciona dentro de la formación docente, como indica Prendes et al. (2018), la repercusión de la competencia digital en el cómo usar, analizar y reflexionar sobre las tecnologías, para su uso efectivo en los procesos de enseñanza-aprendizaje, gestión, investigación y las metodologías docentes; es decir, no es solo el buen uso de herramientas, sino el significado que representa la aplicación efectiva de la tecnología en la práctica docente.

Dentro de los diferentes estudios expuestos, tanto del nivel nacional como internacional, se evidencia un interés por esclarecer las razones que inciden en los bajos resultados arrojados para el manejo de la competencia digital docente, las cuales fueron atribuidos a diferentes variables de estudio; sin embargo, se expone la edad del docente, como la de mayor reiteración, lo cual podría 
explicarse debido a presunción del concepto nativo digital, denotando a las generaciones más jóvenes, bajo apropiación innata de las tecnologías digitales, coincidiendo con valores recopilados en la presente investigación.

Por otro lado, se determina, dentro de la caracterización de los estudios realizados, el nivel de instrucción al que pertenecen las muestras, encontrando: 1433 docentes de los diferentes grados de instrucción dentro de la clasificación primaria, secundaria y mixta, trabajado por Fernández y Fernández (2016); 1447 formularios diligenciados por docentes, en áreas con nivel de básica primaria, básica secundaria y media vocacional, referidos por Said et al. (2017); 611 docentes preuniversitarios, tomados por López et al. (2020); 108 estudiantes de docencia tenidos en cuenta para la investigación realizada por Guillén et al. (2020); y 6000 docentes clasificados en los niveles preescolar, básica primaria, básica secundaria, media o básica secundaria - media, señalados por Sánchez, et al. (2018).

Por consiguiente, se evidencia los esfuerzos de evaluación por parte de entes gubernamentales y académicos, en adelantar programas de formación que subsanen las falencias encontradas en docentes de instituciones de nivel preescolar, básica y media, encontrando el diferencial de los estudios en que la muestra pertenece a docentes universitarios, cuyo contenido disciplinar y funciones exigen, hoy día, una mayor apropiación y uso de estas competencias, concediendo la trascendencia del papel que cumplen las tecnologías como herramientas de sus prácticas pedagógicas; sin embargo, aún es necesario dirigir su relevancia dentro del contexto en el que se realiza el ejercicio educativo, y reflexionar sobre su acción transformadora en la construcción social.

Frente a los resultados obtenidos en la presente investigación, estos se alimentan de posiciones personales o autoevaluaciones desarrolladas mediante el instrumento aplicado; aunque se aprecia un vacío en lo que respecta a la implicación de su conceptualización, aplicación y uso asertivo en el aula, según la situación presentada. Por lo anterior, se recomienda la reorientación hacia un estudio valorativo de la práctica eficiente de las herramientas, mediante situaciones que representen la experticia.

Según la exploración bibliográfica, en la práctica no se reconoce una planeación formativa actualizada en contenido y aplicación de competencias digitales, alineada a los marcos del MEN, que permitan al docente minimizar las implicaciones de la brecha generacional y su adaptación a 
las nuevas tecnologías en los diferentes campos, así como las de alcanzar el dominio tecnológico con uso asertivo de las TIC; por ello, se precisa atender las necesidades de aprendizaje de la población docente, permitiendo impulsar el desarrollo innovador dentro del aula.

En este orden de ideas, la investigación presentada traza su orientación, validando los niveles de desarrollo de las diferentes competencias e intereses del docente, mediante los análisis de los datos arrojados, como base hacia la construcción de un plan de formación gradual, alineado con los requerimientos del marco regulatorio y del entorno actual, que contemple el acercamiento y apropiación de las competencias digitales a los docentes, cuyo ejercicio se encuentre desde la educación básica hasta la superior, y en permanente actualización.

\section{Conclusiones}

A partir de los resultados que arrojó la aplicación del instrumento de recolección de datos, basado en el Modelo Prendes et al. (2018), aplicado a una muestra significativa de la población de la Fundación Universitaria del Área Andina, se puede establecer un relacionamiento directo entre las competencias definidas por el modelo Prendes et al. (2018) y las expuestas por el modelo MEN (2013), ya que los dos clasifican sus competencias en 5 grandes grupos, los cuales cuentan con aspectos muy similares en su caracterización.

Los datos arrojados de la aplicación del instrumento, evidencian la necesidad de fortalecer las competencias digitales en los docentes, ya que en los niveles iniciales, como el Explorador, se ubica un $12 \%$ de los docentes participantes, denotando un bajo porcentaje, especialmente en las habilidades desarrolladas en la competencia Comunicativa, lo cual es de suma relevancia, considerando que falta iniciativa y confianza en la integración de otras herramientas digitales en el aula; diferenciando los tipos y canales de comunicación; haciendo un buen uso de las herramientas, tanto sincrónicas como asincrónicas; desarrollando y aprovechando espacios, como es el caso de los encuentros sincrónicos, ya que estos deben desarrollarse desde las bondades que ofrece la plataforma, y no como un medio de transmisión de información. Por lo anterior, se debe propender porque sea de un buen nivel interactivo y que se haga integración de otras herramientas que puedan dar valor agregado a la temática orientada, dependiendo el objetivo del resultado de aprendizaje. 
Adicional, una de las observaciones a destacar, producto del análisis y desarrollo de la propuesta, es el uso de las bases de datos especializadas para la gestión y evaluación de la información hallada, partiendo de la búsqueda efectiva y la contextualización de esta, como referentes a la hora de citar o argumentar textos, proyectos y demás; los resultados de la aplicación del instrumento muestra que el $77 \%$ de los docentes se ubica en el nivel Integrador, mostrando esta debilidad que se puede fortalecer desde la competencia investigativa y tecnológica, del nivel Integrador, para fortalecer las temáticas.

Por último, como resultado del nivel Innovador, con un $11 \%$ de docentes participantes, se evidencia que falta incentivar el uso de herramientas en la nube, captación, análisis, procesamiento, interpretación y representación de elementos que la componen, para la creación y desarrollo de procesos de investigación que fomenten la creatividad, la innovación y el desarrollo de proyectos, producto del alcance de las competencias digitales.

El desarrollo del programa de formación digital, basado en el modelo del MEN (2013), aportará de manera integral al desarrollo de habilidades, destrezas y actitudes para el desempeño del docente, de acuerdo con sus necesidades y punto de partida. El diseño se basa en un mundo virtual, donde cada uno de los niveles se encuentra organizado para ser cursado, previa aprobación de la solución del reto planteado como enfoque pedagógico para la enseñanza y el aprendizaje de las competencias digitales.

En dicho modelo se inicia, desde el nivel Explorador, con su alcance de descubrimiento y experimentación, haciendo uso de herramientas e inclusión al aula; luego, en el nivel Integrador, se consolida el uso pertinente de la tecnología dentro del aula, con la propuesta de proyectos y su impacto social y tecnológico; y, por último, en el nivel Innovador, de manera creativa e imaginativa, se idean estrategias de aprendizaje en ambientes virtuales, desde el diseño, desarrollo e implementación de contenido, integrando tecnologías inmersivas.

Cada uno de los cursos tiene una duración de 4 semanas, donde deben revisar contenidos, afianzar conocimientos, a través de actividades, y plantear un reto y su solución, el cual debe sustentar a los compañeros y docente guía; se plantea trabajo individual y colaborativo, de acuerdo con número de participantes por nivel y competencia.

De esta manera, se aportan propuestas, de gran utilidad pedagógica, científica y social, al proyecto educativo de las instituciones de educación superior. La construcción de cada uno de los 
módulos de este programa se llevó a cabo teniendo en cuenta los resultados de la primera fase de la investigación, la cual analizó la situación actual de los docentes de la institución y su clasificación, de acuerdo con los dos modelos estudiados (Prendes et al., 2018; MEN, 2013); adicional, se identificó cada uno de los descriptores de desempeño, propios de las competencias, y su respectivo nivel, enunciados en el documento del MEN (2013).

Desde el grupo de investigación, y según el análisis descrito anteriormente, se propuso una ruta de formación digital con un enfoque de aprendizaje basado en retos, que permita un resultado de formación positivo y contextualizado en las problemáticas evidenciadas en el quehacer docente; esto, con el ánimo de que sus resultados aporten nuevas tendencias en innovación educativa, que favorezcan procesos de enseñanza de calidad, apoyados en el desarrollo de las TIC.

\section{Referencias}

Agarwal, R. (2020). Digital Transformation: A Path to Economic and Societal Value. Revista CEA, 6(12). https://doi.org/10.22430/24223182.1700

Cabero Almenara, J., y Martínez Gimeno, A. (2019). Las tecnologías de la información y comunicación y la formación inicial de los docentes: modelos y competencias digitales. Profesorado: Revista de Currículum y Formación de Profesorado, 23(3), 247-268. https://doi.org/10.30827/profesorado.v23i3.9421

Colás Bravo, M. P., de Pablos Pons, J., y Ballesta Pagán, J. (2018). Incidencia de las TIC en la enseñanza en el sistema educativo español: una revisión de la investigación. Revista de Educación a Distancia (RED), 18(56), 1-23. https://revistas.um.es/red/article/view/321471

Domingo, M., y Marqués, P., (2011). Aulas 2.0 y uso de las TIC en la práctica docente. Comunicar 19(37), 169-175. https://www.redalyc.org/pdf/158/15820024020.pdf

Falloon, G. (2020). From digital literacy to digital competence: the teacher digital competency (TDC) framework. Educational Technology Research and Development, 68, 2449-2472. https://doi.org/10.1007/s11423-020-09767-4 
Fernández, F., y Fernández, M. (2016). Los docentes de la Generación Z y sus competencias digitales. Comunicar: Revista Científica Iberoamericana de Comunicación y Educación, 46, 97-105. https://doi.org/10.3916/C46-2016-10

García, V., y Fabila, A. (2011). Modelos pedagógicos y teorías del aprendizaje en la educación a distancia.

Apertura,

$3(2)$.

http://www.udgvirtual.udg.mx/apertura/index.php/apertura/article/view/205/220

Guillén, F. D., Mayorga, M. J., \& Álvarez, F. J. (2020). A Study on the Actual Use of Digital Competence in the Practicum of Education Degree. Technology, Knowledge and Learning, 25(3), 667-684. https://doi.org/10.1007/s10758-018-9390-z

Hernández, C., Arévalo, M., y Gamboa, A. (2016). Competencias TIC para el desarrollo profesional docente en Educación Básica. Praxis \& Saber, 7(14), 41-69 https://doi.org/10.19053/22160159.5217

Hernández, C., Ayala, E., y Gamboa, A., (2016). Modelo de competencias TIC para docentes: Una propuesta para la construcción de contextos educativos innovadores y la consolidación de aprendizajes en educación superior. Revista Katharsis, (22), 221-265. http://revistas.iue.edu.co/revistasiue/index.php/katharsis/article/view/821

Hernández, R., Fernández, C., y Baptista, P. (2014). Metodología de la Investigación (6 Ed.) Mcgrawhill.

Kaiser, H. F. (1974). An index of factorial simplicity. Psychometrika, 39(1), 31-36. https://doi.org/10.1007/BF02291575

López, J., Pozo, S., Vázquez, E., y López, E. (2020). Análisis de la incidencia de la edad en la competencia digital del profesorado preuniversitario español. Revista Fuentes, 1(22), 7587. https://doi.org/10.12795/revistafuentes.2020.v22.i1.07

McGarr, O., \& McDonagh, A. (2019). Digital Competence in Teacher Education. Output 1 of the Erasmus+ funded Developing Student Teachers' Digital Competence (DICTE) project. https://dicte.oslomet.no/wp-content/uploads/2019/03/DICTE-Digital-Competence-inTeacher-Ed.-literature-review.pdf

Ministerio de Educación Nacional -MEN-. (2006). Ser competente en tecnología: ¡una necesidad para el desarrollo! https://www.mineducacion.gov.co/1621/articles160915_archivo_pdf.pdf 
Ministerio de Educación Nacional -MEN-. (2013). Competencias TIC para el desarrollo profesional docente. $\quad$ https://www.mineducacion.gov.co/1759/articles339097_archivo_pdf_competencias_tic.pdf

Mishra, P., \& Koehler. M., (2018). Introducing Technological Pedagogical Content Knowledge. https://www.researchgate.net/publication/242385653_Introducing_Technological_Pedago gical_Content_Knowledge

Montoya, N. E., y González, E. V. (septiembre-diciembre, 2019). Competencias TIC en docentes de nivel técnico y tecnológico. Un estudio de caso en un centro de formación del SENA. Revista Virtual Universidad Católica del Norte, (58), 74-95. https://doi.org/10.35575/rvucn.n58a3

Morales, L., y Medina, E. (2015). Aplicación del modelo Servperf en los centros de atención Telcel, Hermosillo: una medición de la calidad en el servicio. Contaduría y Administración, 60(1), 229-260. $\quad$ http://www.scielo.org.mx/scielo.php?script=sci_abstract\&pid=S0186$\underline{10422015000100010 \& \operatorname{lng}=\mathrm{es} \& \mathrm{nrm}=\mathrm{iso}}$

Ñáñez-Rodríguez, J. J., Solano-Guerrero, J. C., y Bernal-Castillo, E. (2019). Ambientes digitales de aprendizaje en educación a distancia para la formación inicial de docentes: percepciones acerca de su pertinencia. Revista de Investigación, Desarrollo e Innovación, 10(1), 107119. https://doi.org/10.19053/20278306.v10.n1.2019.10015

Observatorio de Innovación Educativa del Tecnológico de Monterrey. (2015). Edutrends. Aprendizaje basado en retos. Editorial Instituto Tecnológico y de Estudios Superiores de Monterrey. https://observatorio.tec.mx/edutrendsabr

Pérez-Rojas, J. G. (2020). Retos de las instituciones de educación superior para su articulación en la Industria 4.0. Revista CEA, 6(11), 9-11.https://doi.org/10.22430/24223182.1584

Perrenoud, P. (2001). La formación de los docentes en el siglo XXI. Revista de Tecnología Educativa, 14(3). https://www.unige.ch/fapse/SSE/teachers/perrenoud/php_main/php_2001/2001_36.html

Prendes, M. P., Gutiérrez, I., y Martínez, F. (2018). Competencia digital una necesidad del profesorado universitario en el siglo XXI. RED. Revista de Educación a Distancia, 56, 222. https://revistas.um.es/red/article/view/321591 
Roa, K., y Tovar, P. (2019). Diseño y validación de un instrumento de diagnóstico de uso educativo de las TIC por parte de los docentes. En R. Roig-Vila (Coord.), REDES-INNOVAESTIC 2019. Libro de actas (pp. 99-100). Universidad de Alicante. https://rua.ua.es/dspace/bitstream/10045/92187/1/XARXES-INNOVAESTIC-2019.pdf

Said, E., Valencia, J., y Señan, G. (2017). Nivel de aprovechamiento docente de las TIC en
Colombia.
Profesorado,
21(3),
219-238.

https://recyt.fecyt.es/index.php/profesorado/article/view/59796

Salas, M. (2019). Convergencia entre nativos digitales. Revista Sinergias Educativas, 5(1), 224240. http://www.sinergiaseducativas.mx/index.php/revista/article/view/109/281

Sánchez H., Haddad D., González M., y Olarte F. (2018). Panorama del nivel de competencias TIC

en

docentes

colombianos.

https://encuentros.virtualeduca.red/storage/ponencias/bahia2018/HZ41c1dRY5Kbf1DnhC iMvwZpcrTWwwr28ciGxpQD.pdf

Santos, A. I., \& Serpa, S. (2017). The importance of promoting digital literacy in higher education. International Journal of Social Science Studies, 5(6), 90-93. https://www.semanticscholar.org/paper/The-Importance-of-Promoting-Digital-Literacyin-Santos-Serpa/f0f0049376d76fefa788c7a18cf8922cf2e009de

Spante, M., Hashemi, S. S., Lundin, M., \& Algers, A. (2018). Digital competence and digital literacy in higher education research: Systematic review of concept use. Cogent Education, 5(1), 1519143. https://doi.org/10.1080/2331186X.2018.1519143

Svensson, M., \& Baelo, R. (2014). Teacher students' perceptions of their digital competence. Procedia - Social and Behavioral Sciences, 180, 1527-1534. https://www.researchgate.net/publication/277075598_Teacher_Students'_Perceptions_of_ their_Digital_Competence

Vargas, J., Chumpitaz, L., Suárez, G., y Badia, A. (2014). Relación entre las competencias de docentes de Educación básica y el uso educativo de las tecnologías en las aulas. Revista de Curriculum y Formación del Profesorado, 18(3), 361-377. https://digibug.ugr.es/bitstream/handle/10481/34544/rev183COL9.pdf?sequence=1\&isAll owed $=\mathrm{y}$ 


\section{El docente en la}

\section{era 4.0}

Zabalza, M. (2003). Competencias docentes del profesorado universitario. Calidad y desarrollo profesional. $\quad \underline{\text { https://www.studocu.com/co/document/universidad-pedagogica-nacional- }}$ colombia/educacion-y-pedagogia/otros/zabalza-miguel-a-competencias-docentes-delprofesorado-universitaria-calidad-y-desarrollo-profesional-narcea-espana-

$\underline{2003 / 5537807 / \text { view }}$ 